\title{
Polyethersulfone/HFO Mixed Matrix Membrane for Enhanced Oily Wastewater Rejection
}

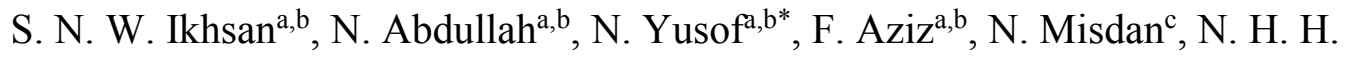 \\ Hairom $^{\mathrm{c}}$ \\ aAdvanced Membrane Technology Research Centre (AMTEC), Universiti Teknologi \\ Malaysia, 81310 UTM Johor Bahru, Johor, Malaysia \\ ${ }^{b}$ Faculty of Chemical and Energy Engineering (FCEE), Universiti Teknologi \\ Malaysia, 81310 UTM Johor Bahru, Johor, Malaysia \\ ${ }^{c}$ Faculty of Engineering Technology, Universiti Tun Hussein Onn Malaysia, 86400 \\ Parit Raja, Johor, Malaysia
}

\begin{abstract}
The recent growth of oil and gas industry has led to the increase of oily wastewater release. Membrane technology has been in the spotlight in recent advancement to treat the oily wastewater. Fouling due to surfactant adsorption and/or oil droplets plugging the pore has become one of the major hindrances in most of the research on oily wastewater treatment. In this work, self-synthesized hydrous ferric dioxide nanoparticles (HFO NPs) via chemical precipitation method were incorporated in polyethersulfone (PES) to fabricate a novel nanocomposite mixed matrix membranes (MMMs) for ultrafiltration (UF). The morphologies and physicochemical properties of prepared HFO NPs and MMMs were characterized using Scanning Electron Microscopy (SEM) and Transmission electron microscope (TEM), contact angle goniometer, before further subjected to water permeation test and oil rejection test. It was found that contact angle of membrane decreased remarkably with an increase in HFO nanoparticle loading from $70^{\circ}$ to $38^{\circ}$ at which proved its improved hydrophilicity which led to a significant rise in permeate flux, achieving $168.06 \mathrm{~L} / \mathrm{m}^{2} \mathrm{~h}$ bar in comparison to 63.67 $\mathrm{L} / \mathrm{m}^{2} \mathrm{~h}$ bar shown by the plain PES membrane. Total rejection of oil (100\% rejection) demonstrated by the MMMs has confirmed the superior potential of PES/HFO UF membrane for total purification of oily wastewater especially to be reused in oilfield and refinery processes as well as to be released to the environment.
\end{abstract}

Keywords: Oily wastewater treatment, UF, mixed matrix membranes, oil-water separation

\subsection{INTRODUCTION}

In these modern millennia, the advancement of technology has been the force that builds the rapid growth of many industries, especially oil and gas industry. With growth of this industry it has raised concerns especially to environment as some oil and gas industry operations have been responsible for water contamination through by-results of refining and oil slicks [1]. The need to purify and treat the oily wastewater has intensified as the three important environmental drivers namely the governments, increasingly aware public and the industry has sought to avoid, wherever feasible, wastes and pollution, while increasing consumption, improving quality of life, and protecting the environment [2]. Oily wastewater pollution can be manifested in unusual way such as affecting drinking water and groundwater resources besides endangering aquatic resources and human health. Numerous techniques have been adapted to separate oil/water 
mixture which includes air flotation, gravity separation, oil-adsorbing materials, coagulation, and flocculation [3]. These strategies are inadequate in treating emulsified oil/water [4]. The permit limits of oil and gas $(O \& G)$ for treated produced water according to the United States Environmental Protection Agency regulatory limits are $29 \mathrm{mg} \mathrm{L}^{-1}$ for a monthly average and $42 \mathrm{mg} \mathrm{L}^{-1}$ for a daily maximum. Oily wastewaters are characterized by a high content of salts and oil, which makes it mandatory to draw a specifically purposed treatment train, different, for example, from those commonly used for municipal wastewaters treatment

Membrane technology coupled with filtration method has attracting attention in effort to separate various emulsions especially surfactant stabilized emulsions. It has excellent discharge quality and yet a very simple process. Polymeric membrane has advanced seamlessly for the past few years and it has grown steadily with vast utilizations especially in water treatment. The utilization of membrane technology has received significant attention due to its excellent selectivity and low energy requirement. It is effective in separating the oils, emulsions, and silts [5]. However, its fouling tendency remains a major challenge for many researchers. This is due to surfactant adsorption and/or pore plugging by oil droplets will cause a severe decline of the flux and rejection rate. There are need to reduce the fouling to enhance separation performance. One of the effective ways in increasing the antifouling property of the membrane is by surface modification. Membranes functionalized with applicable macromolecules without a doubt can impart applications extending from tunable flux and separations [6].
Ultrafiltration exploits separation centered on the pore size and molecular weight of the solution that mainly centered on the adsorptionsieving mechanism which is suitable for rejection of oil droplets and at the same time has the full potential in getting the water pass through the membrane [7].

The main objective of this study is to develop a new mix-matrix membrane that has excellent selectivity and permeability with enhanced hydrophilicity that led to better performance in separation of oily emulsions besides having improved antifouling ability. The main concern in fabrication of the said MMMs is its ability to eliminate membrane fouling and enhance its overall performance. In this study, flat sheet PES-HFO ultrafiltration membranes were fabricated using different loading of HFO (0, 0.5 and 1.0 wt. \%). and structural analysis of the modified membranes was performed with the aids of SEM, FTIR and goniometer. Membrane separation performances were evaluated with respect to water flux and oil rejection.

\subsection{METHODS}

\subsection{Materials}

Commercial PES pellets (Ultrason ${ }^{\circledR E}$ ) purchased from BASF SE Germany is the main component in membrane formation. N-Methyl-2-pyrrolidone (NMP) and polyvinylpyrolidone (PVP) $(\mathrm{MW}=24,000 \mathrm{~g} / \mathrm{mol})$ supplied by Merck is utilized as polymer solution and pore forming agent. Ferric chloride hexahydrate

$\left(\mathrm{FeCl} .6 \mathrm{H}_{2} \mathrm{O}\right)$, hydrochloric acid $(\mathrm{HCl})$ and ammonia solution $\left(\mathrm{NH}_{3}\right)$ and is used for synthesizing HFO NPs 
Table 1 Composition of dope solution

\begin{tabular}{|c|c|c|c|c|c|}
\hline Membrane & $\begin{array}{c}\text { PES/HFO } \\
\text { ratio }\end{array}$ & PES (wt\%) & $\begin{array}{c}\text { NMP } \\
\text { (wt\%) }\end{array}$ & PVP (wt\%) & HFO (wt\%) \\
\hline PES & 0 & 15.00 & 83.5 & 1.50 & - \\
\hline PES-HFO 0.5 & 0.5 & 13.95 & 80.59 & 1.30 & 6.98 \\
\hline PES-HFO 1.0 & 1.0 & 13.04 & 72.60 & 1.22 & 13.04 \\
\hline
\end{tabular}

\subsection{Preparation of Dope Solution}

A predetermined amount of PVP was first dissolved in NMP solvent. The HFO nanoparticles has been synthesized by our group has been described elsewhere [8]. HFO inorganic particle were then added into the solution and dispersed sufficient well with stirring, followed by sonication at $50{ }^{\circ} \mathrm{C}$ for several hours. Dried PES polymer pellets were then added into the mixture and stirred at $500 \mathrm{rpm}$ for $24 \mathrm{~h}$ until a homogenous suspension was obtained. The dope solution for the pristine PES membrane was prepared in the same way without adding HFO particles. The composition of dope solution is shown in Table 1.

\subsection{Characterization of MMMs}

Transmission electron microscope (TEM) (Model: HT 7700, Hitachi) was used to analyze the morphology of the synthesized HFO nanoparticles. The membrane surface morphology and cross-area were inspected utilizing a field emission scanning electron microscope (FESEM, ZEISS SUPRA $35 \mathrm{VP})$.

\subsection{Membrane Hydrophilicity}

To determine membrane surface hydrophilicity, sessile drop method was employed to measure the water contact angle of the membranes using an automated contact angle goniometer (Model: OCA 15plus, DataPhysics). A droplet of DI water with a volume of $0.5 \mathrm{~mL}$ was carefully formed at ten spots randomly chosen on the membrane surface using a motordriven microsyringe and the contact angle was measured after $5 \mathrm{~s}$ once the water was dropped. The average measurement was then recorded.

\subsection{Oil Rejection Test}

To determine the oil rejection rate, the cross flow UF study was carried out using method used by [9]. The variable that will be taken into consideration for the oil rejection test is oil concentration in permeate. The permeate will be sampled every $10 \mathrm{~min}$ for the course of $3 \mathrm{~h}$. The specific end goal of this test is to assess the impact of oil concentration on the permeate flux and oil dismissal of membranes. Then, the oil concentration of samples analyzed using UV-vis spectrophotometer at $305 \mathrm{~nm}$

\subsection{RESULTS AND DISCUSSION}

\subsection{Morphological Analysis of MMMs}

The SEM micrographs of the surface and cross-section of the PES membrane and the MMMs are shown in Figure 1. The formation of asymmetric structure, which made up of a porous skin layer and undergirded by a sub layer with finger-like consistency, is the usual depiction of process adopted in this work for 


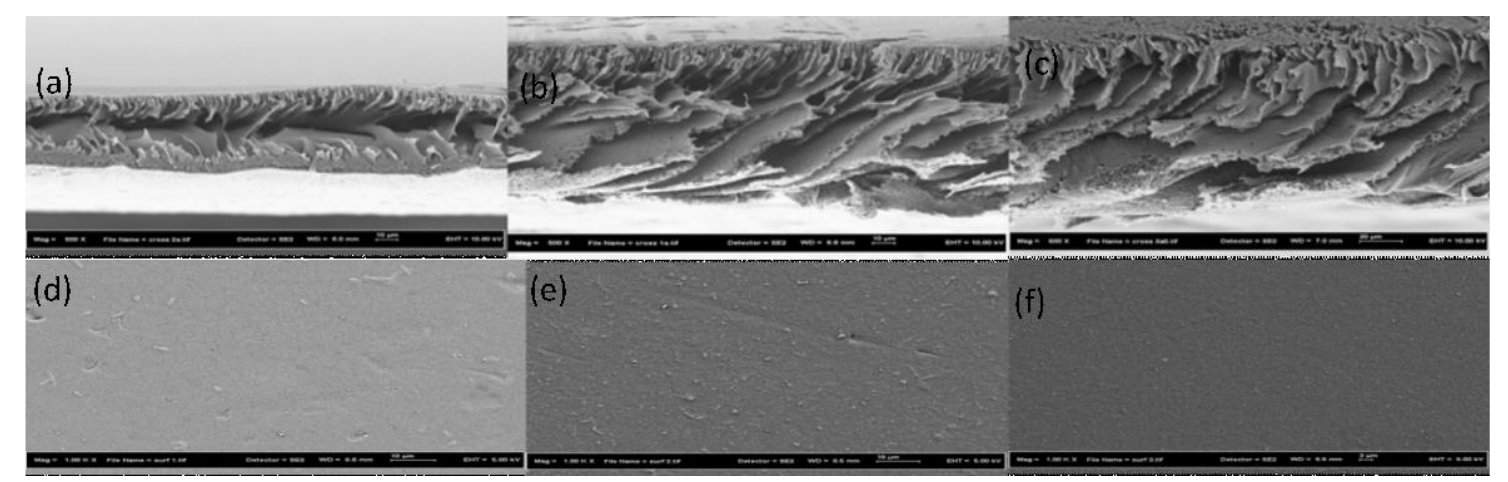

Figure 1 Scanning Electron Micrographs (SEM) of surface and cross sections of membranes at 1000x magnification, Cross Section: (a) PES-HFO 0, (b) PES-HFO 0.5, (c) PES-HFO 1.0, Surface (d)PES-HFO 0, (e) PES-HFO 0.5, (f) PES-HFO 1.0

membrane fabrication which is the phase inversion method. As the magnification of the micrographs increased, it is observed that there's integration of HFO on the modified membrane as shown in Figure 1.

It is observed that the pristine PES membrane (PES-HFO 0) as depicted in Figure 1(a) has observable formation of macrovoids whereby the modified membranes (PES-HFO 0.5 and 1.0) shows lesser formation of macrovoids as depicted in Figure 1(b). As observed in Figure 1(b), PES-HFO membrane 0.5 has roughest surface compared to the other. All membranes were observed to possess thin or selective layer based on the cross-sectional micrograph. This is due to the increased viscosity of the dope solution of the modified membrane. The lesser macrovoids formation will lead to more selective membrane and the formation decrease as the loading of HFO increased. It is also observed that the finger-like formation of the modified membranes is longer compared to the pristine membrane. Theoretically, HFO exists as spherical shape and this is confirmed as TEM analysis as shown in Figure 2(c) is done to the fabricated HFO nanoparticles. The integration of HFO into the membrane is shown as the spherical dots on the SEM micrographs as shown in Figure 2(b) as the magnification increased from $100 \mathrm{x}$ to 1000x. The even distribution of HFO is enhanced as agglomeration is decreased with increased.

\subsection{Membrane Hydrophilicity}

Surface hydrophilicity of membrane is the key role in defining the pure water flux and antifouling property. Membranes in an aqueous environment will naturally possessed attractive or repulsive response to water [11]. The composition of the membrane and its corresponding surface chemistry has eminent effects especially in the water interaction that indigenously relate to its wettability. Hydrophilic membrane usually contains active groups that possess the ability to form "hydrogenbonds" with water. contact angle of PES neat membrane and the modified membranes has significant difference depicted the contact angle of each membrane and Figure 3 shows the graphical presentation of the water contact angle. The increasing of HFO loading has obviously increased the wettability of the membrane as the contact angle of membrane decreased. 


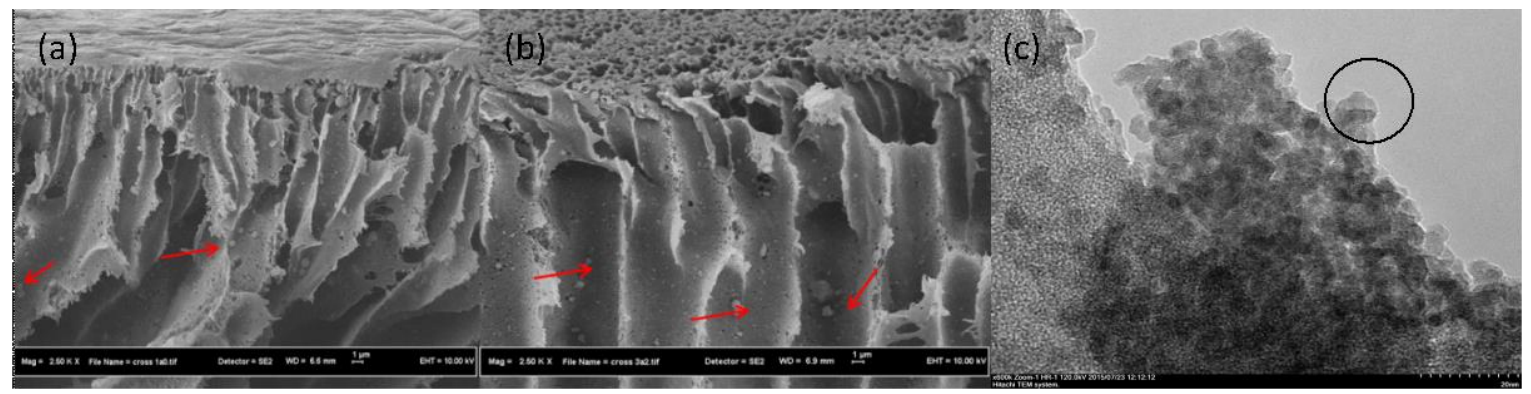

Figure 2 Scanning Electron Micrographs (SEM) of (a) PES-HFO 0.5, (b) PES-HFO 1.0, (c) TEM image of HFO

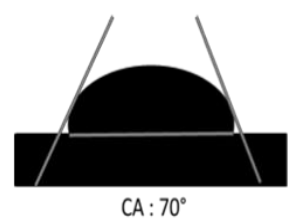

(a)

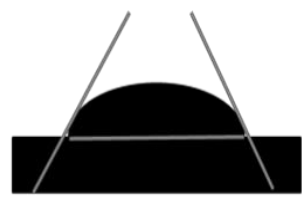

$\mathrm{CA}: 59^{\circ}$ (b)

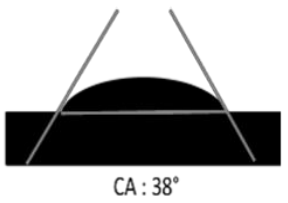

(c)

Figure 3 Water contact angle of membranes, (a) PES-HFO 0, (b) PES-HF0 0.5, (c) PESHFO 1.0

The contact angle of PES neat membrane and the modified membranes has significant difference depicted the contact angle of each membrane and Figure 3 shows the graphical presentation of the water contact angle. The increasing of HFO loading has obviously increased the wettability of the membrane as the contact angle of membrane decreased.

\subsection{Pure Water Flux Test}

Figure 4 shows the change in membrane flux over time. At the outset, the permeation fluxes dwindled gradually up to a point at which the flux remains in the same value. As the permeation take place in UF process, the fluxes of modified membranes PES-HFO 0.5 and PES-HFO 1.0 were always higher than those of neat PESHFO 0, which was also contributed to the improved hydrophilicity of the membrane. This is due to the abundant $-\mathrm{OH}$ group from the HFO nanoparticles as confirmed by FTIR analysis depicted in Figure 3. This was attributed to more water absorption hence increased hydrophilicity.

It is also observed that the increasing loading of HFO has also increased the water permeation of the membrane at which PES-HFO 1.0 (with PES: HFO ratio is $1: 1$ ) is significantly higher than PES-HFO 0.5 (ratio PES: HFO is 2:1) Stable flux of the PES-HFO 1.0 membrane is 168.06 $\mathrm{L} / \mathrm{m}^{2} \mathrm{~h}$, which is 1.61 times than that of the PES-HFO 0.5 membrane, 104.69 $\mathrm{L} / \mathrm{m}^{2} \mathrm{~h}$ and 2.64 times more than neat PES membrane, $63.67 \mathrm{~L} / \mathrm{m}^{2} \mathrm{~h}$

\subsection{Oil Rejection Test}

Figure 5 depicts the concentration of permeates as it is subjected to different loading of membrane over the course of 3 hours. As time increased the concentration of permeates decrease and at a point decline to 0 which indicates no oil presence. As the loading of the HFO increased, the time taken for the permeates to reach zero (100\% oil rejection) decreased. For instance, it took 160 minutes for PESHFO 0.5 to reach total oil rejection, but 


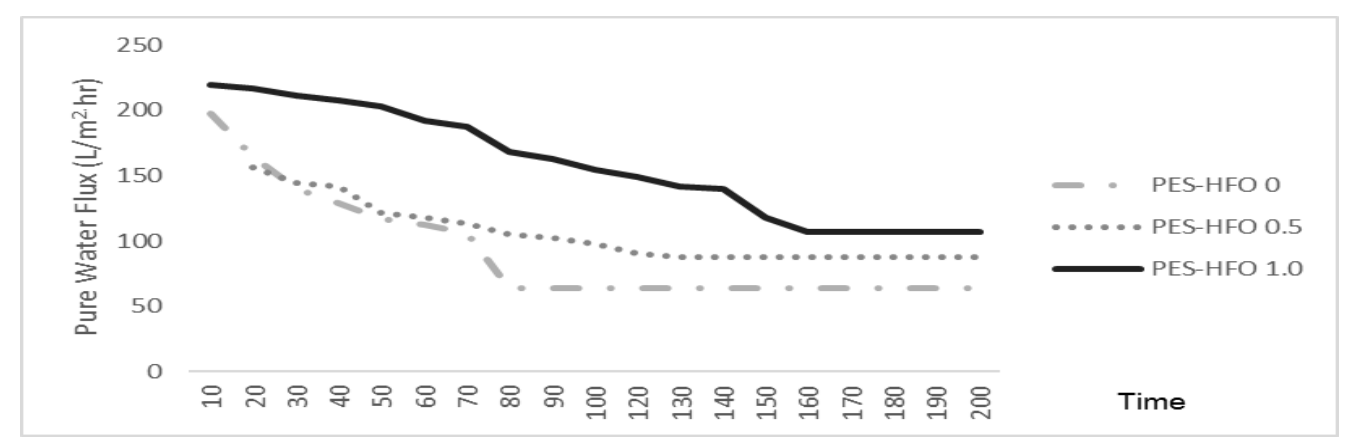

Figure 4 Pure water flux of different loading membrane over time

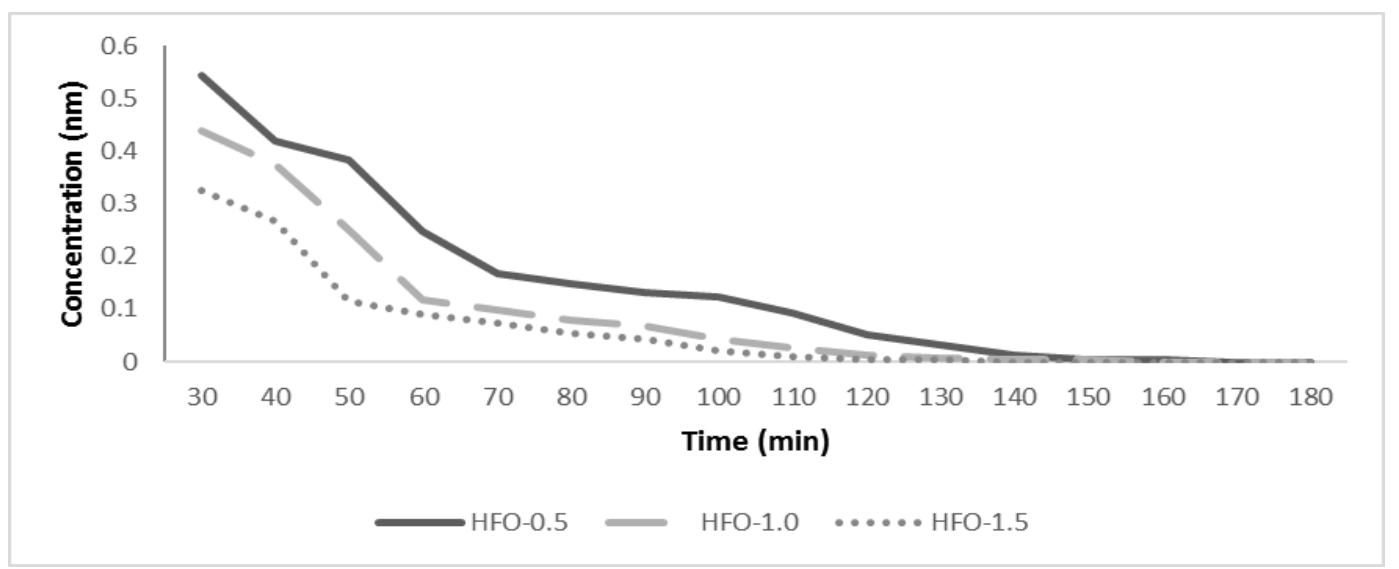

Figure 5 Concentration of feed permeates of different loading membrane over time taken using UV-VIS spectrophotometer at $305 \mathrm{~nm}$

PES-HFO 1.0 took only 120 minutes to reach total oil rejection. The higher water flux has caused the passage of the solutes to be comparatively less which causes the higher rejection of oil droplet [9]. This indicates that increasing loading of nanoparticles lead to enhanced selectivity of membrane due to the active functional group increasing.

\subsection{CONCLUSION}

In this study, reconnaissance was made in water permeability and oil rejection ability of PES-HFO modified membrane for oily wastewater treatment. The results revealed that the embedding of HFO has significantly increased the hydrophilicity of the membrane as well as increased the oil rejection. It is also found that the integration of HFO not only increased the water permeability of the membrane but also greatly improved the selectivity of the membrane. With significant improvement on the membrane hydrophilicity due to addition of HFO, the modified MMMs has shown robust potential to be further studied for oily wastewater purposes and to be applied in oil and gas industry to treat refinery and oilfield produced water for reuse and release to environment.

\section{ACKNOWLEDGEMENT}

The authors would like to acknowledge the financial support from Malaysian 
Ministry of Education (Higher Institution Centre of Excellence) under Grant No. R. J090301.7846.4J180 and Universiti Teknologi Malaysia under Grant No Q. J130000.2546.12H54. The authors would also like to acknowledge the technical and management support from Research Management Centre (RMC), Universiti Teknologi Malaysia.

\section{REFERENCES}

[1] A. Ahmed, J. Ahmad, Y. Basma, T. Ramzi. 2007 Assessment of Alternative Management Techniques of Tank Bottom Petroleum Sludge in Oman. $J$ Hazardous Mat. 141: 557-564.

[2] D. Paul, S.K. Sikdar. 1998. Clean Production with Membrane Technology. Clean Tech Environ Policy. 1: 39-48

[3] G. H. Liu, Z. Ye, K. Tong, Y. H. Zhang. 2013. Biotreatment of Heavy Oil Wastewater by Combined Up Flow Anaerobic Sludge Blanket and Immobilized Biological Aerated Filter in a Pilot-scale Test. Biochem Eng J. 72: 48-53.

[4] A. Fakhru'l-Razi, A. Pendashteh, Z. Zainal Abidin, L. Abdullah, D. Awang Biak, S. Madaeni. 2010. Application of membranecoupled sequencing batch reactor for oilfield produced water recycle and beneficial re-use. Biores Tech. 101: 6942-694.

[5] M. Knoblock, P. Sutton, P. Mishra. 1994. Membrane Biological Reactor System for Treatment of Oily Wastewater. Water Environment Resources. 66: 133-139.

[6] D. Bhattacharyya. 2007. Functionalized Membranes and
Environmental Applications. Clean Techn Environ Policy. 9: 81-83

[7] P. S. Sudilovskiy, G. G. Kagramanov, A. M. Trushin, V. A. Kolesnikov. 2007. Use of Membranes for Heavy Metal Cationic Wastewater Treatment: Flotation and Membrane Filtration. Clean Techn Environ Policy. 9: 189-198

[8] Abdullah, N., Gohari, R. J., Yusof, N., Ismail, A. F., Jaafar, J., Lau, W. J. 2016. Polysulfone/hydrous Ferric Oxide Ultrafiltration Mixed Matrix Membrane: Preparation, Characterization, and Its Adsorptive Removal of Lead (II) from Aqueous Solution. Chem Eng Journal. 289: 28-37

[9] R. J. Gohari, W. J. Lau, T. Matsuura, E. Halakoo, A. F. Ismail. 2013. Adsorptive Removal of $\mathrm{Pb}$ (II) from Aqueous Solution by Novel PES/HMO Ultrafiltration Mixed Matrix Membrane. Separation and Purification Technology. 120: 59-68.

[10] R. Thakura, S. Chakrabortty, P. Pa. 2015. Treating Complex Industrial Wastewater in a New Membrane Integrated Closed Loop System for Recovery and Reuse. Clean Techn Environ Policy. 17: 2299-2310.

[11] G. Hurwitz, G. R. Guillen, E. M. V. Hoek. 2010. Probing Polyamide Membrane Surface Charge, Zeta Potential, Wettability, and Hydrophilicity With Contact Angle Measurements. J. Membr. Sci. 349: 349-357. 